\title{
Nanofabrication of Graphene Quantum Dots with High Toxicity Against Malaria Mosquitoes, Plasmodium falciparum and MCF-7 Cancer Cells: Impact on Predation of Non-target Tadpoles, Odonate Nymphs and Mosquito Fishes
}

\author{
Kadarkarai Murugan ${ }^{1,2}$ - Devaraj Nataraj ${ }^{3}$. \\ Anitha Jaganathan ${ }^{1}$ - Devakumar Dinesh ${ }^{1}$. \\ Sudalaimani Jayashanthini ${ }^{1}$ - Christina Mary Samidoss ${ }^{1}$. \\ Manickam Paulpandi $^{1}$ Chellasamy Panneerselvam ${ }^{1,4}$. \\ Jayapal Subramaniam ${ }^{1,5}$ - Al Thabiani Aziz ${ }^{4}$. \\ Marcello Nicoletti ${ }^{6} \cdot$ Suresh Kumar $^{7}$. \\ Akon Higuchi $^{8} \cdot$ Giovanni Benelli $^{9}$
}

Received: 5 October 2016/Published online: 21 October 2016

(C) Springer Science+Business Media New York 2016

\begin{abstract}
Recently, it has been highlighted an overlooked connection between the biting activity of Anopheles mosquitoes and the spread of cancer. The excellent physico-chemical properties of graphene quantum dots (GQDs) make them a suitable candidate for biomedical applications. We focused on the toxicity of GQDs
\end{abstract}

Giovanni Benelli

benelli.giovanni@gmail.com

1 Division of Entomology, Department of Zoology, School of Life Sciences, Bharathiar University, Coimbatore, Tamil Nadu 641046, India

2 Department of Zoology, Thiruvalluvar University, Serkkadu, Vellore, Tamil Nadu 632115, India

3 Department of Physics, Bharathiar University, Coimbatore, Tamil Nadu 641046, India

4 Department of Biology, Faculty of Science, University of Tabuk, Tabuk 71491, Saudi Arabia

5 Division of Vector Biology, Department of Zoology, Faculty of Science, Annamalai University, Annamalai Nagar, Cuddalore, Tamil Nadu 608 002, India

6 Department of Environmental Biology, Sapienza University of Rome, Piazzale Aldo Moro 5, 00185 Rome, Italy

7 Department of Medical Microbiology and Parasitology, Universiti Putra Malaysia (UPM), Serdang, Malaysia

8 Department of Chemical and Materials Engineering, National Central University, No. 300 Jhongli, Taoyuan 32001, Taiwan

9 Department of Agriculture, Food and Environment, University of Pisa, Via del Borghetto 80, 56124 Pisa, Italy 
against Plasmodium falciparum and its vector Anopheles stephensi, and their impact on predation of non-target mosquito predators. Biophysical methods, including UVvis, photoluminescence, FTIR and Raman spectroscopy, XRD analysis and TEM, confirmed the effective GQD nanosynthesis. $\mathrm{LC}_{50}$ against $A$. stephensi ranged from 0.157 (larva I) to $6.323 \mathrm{ppm}$ (pupa). The antiplasmodial activity of GQDs was evaluated against CQ-resistant (CQ-r) and CQ-sensitive (CQ-s) strains of P. falciparum. $\mathrm{IC}_{50}$ were 82.43 (CQ-s) and $85.17 \mu \mathrm{g} / \mathrm{ml}$ (CQ-r). In vivo experiments conducted on Plasmodium berghei infecting albino mice showed moderate activity of GQDs if compared to chloroquine. Concerning non-target effects, the predation efficiency of Gambusia affinis, Anax immaculifrons and Hoplobatrachus tigerinus post-treatment with GQDs was enhanced. Lastly, GQDs were toxic against MCF-7 breast cancer cell lines with an $\mathrm{IC}_{50}=24.81 \mu \mathrm{g} / \mathrm{ml}$, triggering apoptosis in treated cells. Overall, we highlighted the multipurpose potential of GQDs for the development of newer drugs in the fight against Anopheles vectors, Plasmodium parasites and breast cancer cells.

Keywords Anopheles stephensi · Biosafety · Nanoparticles · Non-target effects

\section{Introduction}

Graphene quantum dots (GQDs) recently emerged as superior and universal fluorophores, due to their unique combination of a number of key merits, including excellent photo-stability, small size, biocompatibility, highly tunable photoluminescence (PL), exceptional multi-photon excitation (up-conversion), electrochemiluminescence, chemical inertness, and simple functionalization routes with biomolecules [1]. For these reasons, GQD synthesized by various top-down and bottom-up approaches [2] are presently at the center of research efforts to develop low-toxicity, environmentally friendly alternatives to conventional semiconductor quantum dots $[3,4]$.

Because of their small size and biocompatibility, they may also serve as effective carriers for drug delivery, allowing simultaneous visual monitoring of releasing kinetics [5]. GQDs can be also useful in chemotherapeutics for the treatment of cancer as well as for the differentiation and imaging of stem cells [6]. Moreover, GQDs functionalized with various functional groups (e.g. $\mathrm{NH}_{2}, \mathrm{COOH}$, and $\mathrm{CO}-\mathrm{N}$ $\left.\left(\mathrm{CH}_{3}\right)_{2}\right)$ showed cytotoxicity towards A549 cells [7]. However, it should be mentioned that most of the existing cytotoxicity studies are based on MTT assay, and a systematical cytotoxicity evaluation is necessary for the biocompatibility assessment of GQDs [8].

Interestingly, GQDs have been also proposed as possible candidates to develop newer and safer larvicides in mosquito control programs [9, 10], even if field evidences on a wider scale are lacking [11]. Mosquitoes (Diptera: Culicidae) act as vectors for a number of important pathogens and parasites, including malaria, avian malaria, yellow fever, dengue, chikungunya, Zika virus, Rift valley fever, Japanese encephalitis, Western equine encephalomyelitis, bancroftian and brugian filariae, canine heartworm disease (Dirofilaria immitis) and setariosis (Setaria spp.) [11-16]. 
Anopheles stephensi is vector of Plasmodium parasites (Protozoa) responsible for causing malaria. There were about 198 million cases of malaria in 2013 and an estimated 584,000 deaths. However, malaria mortality rates have fallen by $47 \%$ globally since 2000 and by $54 \%$ in the African region. Most deaths occur among children living in Africa, where a child dies every minute from malaria. Malaria mortality rates among children in Africa have been reduced by an estimated $58 \%$ since 2000 [17]. However, the resurgence of malaria after eradication in many countries is still documented $[18,19]$. The clinical manifestations of malaria are due to the invasion and destruction of red blood cells by the parasite and the consequent host reaction to the malarial parasite infection [20]. However, the extent of hemolysis in malaria is much greater than that seen in other parasite-induced hemolysis pathways [21]. In addition, it has been recently pointed out an overlooked connection between the biting activity of Anopheles mosquitoes and the spread of cancer, with special reference to USA [22, 23], and several relevant analogies at the physiological level among cancer pathology and mosquito-borne diseases have been also outlined [24], highlighting the urgent need of effective multipurpose drugs for joint treatment of cancer and mosquito-borne diseases (see [25] for a recent review).

The better strategy to lower the incidence of mosquito-transmitted diseases and to avoid further complications is to avoid mosquito bites using adult repellents as well as microbial and chemical pesticides. Mosquito young instars have less mobility in their breeding habitat, thus control measures at this stage are relative easy [26]. In their early days of use, chemical pesticides (e.g. carbamates, organophosphates and pyrethroids) showed success in reducing vector populations. However, their frequent overuse increased selection pressure on mosquitoes creating resistance to commonly used molecules [27-29]. Moreover, chemical insecticides also lead to important concerns for the environment and human health $[13,30,31]$. Therefore, in the latest years, a number of eco-friendly mosquito control tools have been proposed [13]. Recently, a number of plant extracts and related metabolites have been exploited for efficient and rapid extracellular synthesis of mosquitocidal nanocomposites with high effectiveness, even if field conditions (e.g. [11, 15, 32-37]).

However, most of the researches focused on the one-pot and cheap nanosynthesis of metal nanoparticles (see [25] for a recent review), while carbon ones have been scarcely studied [9, 10]. Starting from the connection between Anopheles biting activity and the spread of cancer in USA [24], in this research we focused on the toxicity of nanofabricated GQDs against human breast cancer cells (MCF-7 strain), chloroquine-resistant (CQ-r) and CQ-sensitive (CQ-s) strains of Plasmodium falciparum and young instars of its mosquito vector A. stephensi. The antiplasmodial activity of GQDs was also studied through in vivo experiments on P. berghei infecting albino mice. As regards to non-target effects, the predation efficiency of mosquito natural enemies i.e. Gambusia affinis adults, Anax immaculifrons nymphs and Hoplobatrachus tigerinus tadpoles, post-treatment with ultra-low doses of GQDs was evaluated. In addition, a wide array of biophysical methods, including UV-vis, photoluminescence, FTIR and Raman spectroscopy, XRD analysis and TEM, was employed to confirm the effective and cheap nanosynthesis of GQDs. 


\section{Materials and Methods}

\section{Chemicals}

Graphite, $\mathrm{HCl}, \mathrm{H}_{2} \mathrm{SO}_{4}, \mathrm{KMnO}_{4}, \mathrm{H}_{2} \mathrm{O}_{2}, \mathrm{FeSo} 4$, Giemsa stain, PBS, sodium chloride, EDTA, Tris, DMSO and Triton $\mathrm{X}-100, \mathrm{NaOH}$, Tris buffer, sodium hypochlorite, saponin and SYBR Green were all of analytical grades and were purchased from Sigma Aldrich (USA). Fetal bovine serum, penicillin, streptomycin were purchased from Himedia (India). Throughout the study, double distilled water, milli-Q grade water was used for all the experiments, with the exception of mosquito assays, for which dechlorinated water was employed.

\section{Nanosynthesis and Characterization of Graphene Quantum Dots}

Graphene oxide was prepared following the modified method by Hummers [38]. $1.0 \mathrm{~g}$ of graphite and $60 \mathrm{~mL} \mathrm{H}_{2} \mathrm{SO}_{4}(98 \%)$ was stirred in an ice bath, and $5.8 \mathrm{~g}$ $\mathrm{KMnO}_{4}$ was slowly added with stirring for $0.5 \mathrm{~h}$. The solution was heated to $30^{\circ} \mathrm{C}$ for $2 \mathrm{~h}, 40 \mathrm{~mL}$ of deionizer water was added slowly, the reaction was heated to $90{ }^{\circ} \mathrm{C}$ for $30 \mathrm{~min}$, then $80 \mathrm{~mL}$ of deionizer water was added. When the temperature was cooled down to $60{ }^{\circ} \mathrm{C}, 10 \mathrm{~mL} \mathrm{H}_{2} \mathrm{O}_{2}(30 \%)$ were added to obtain an orange yellow solution. $200 \mathrm{~mL}$ of $5 \% \mathrm{HCl}$ solution was added, the supernatant was decanted and centrifuged with deionizer water to $\mathrm{pH} 4-6$, and the mixture solution was further dialyzed in a dialysis bag for 2 days. Low density graphene oxide was obtained by lyophilizing at $-48{ }^{\circ} \mathrm{C}, 21 \mathrm{~Pa}$, and $\mathrm{GO}$ was obtained as gray-yellow powder.

To fabricate GQDs, we followed the method by Murugan et al. [10]. We suspended grapheme oxide $(1.0 \mathrm{~g})$ in concentrated $\mathrm{H}_{2} \mathrm{SO}_{4}$ for a period of 1-2 $\mathrm{h}$ in an ice-water bath and then treated them with $50 \%$ (wt) $\mathrm{KMnO}_{4}$. The $\mathrm{H}_{2} \mathrm{SO}_{4}$ conditions aid in shearing the graphene oxide. The reaction mixture was stirred at room temperature for $2 \mathrm{~h}$ and then heated to $45-50{ }^{\circ} \mathrm{C}$ for additional $1 \mathrm{~h}$. Distilled water $(40 \mathrm{~mL})$ was slowly dropped into the resulting solution. Finally, the reaction temperature was rapidly increased to $90{ }^{\circ} \mathrm{C}$ with effervescence for $30 \mathrm{~min}$. When all the $\mathrm{KMnO}_{4}$ was consumed, we quenched the reaction by pouring over ice containing a small amount of $\mathrm{H}_{2} \mathrm{O}_{2}$ followed by distilled water $(70 \mathrm{~mL})$ obtaining a yellow transparent solution instantly. After cooling down to room temperature, the mixture was ultra-sonicated mildly for a few minutes, the $\mathrm{pH}$ was tuned to 8.0 by $\mathrm{NaOH}$ in an ice bath, and we found a black flocculent deposit. Then, the $\mathrm{pH}$ was increased to 4.0 adding $\mathrm{HCl}$. The suspension was filtered through a $0.22 \mu \mathrm{m}$ microporous membrane to remove the large tracts of graphene oxide, and deep yellow solution (yield ca. $36 \%$ ) was separated. The mixture solution was further dialyzed in a dialysis bag (retained molecular weight: 3,000 to 8,000 Da), and greenish fluorescent GQDs were obtained (yield ca. $34.8 \%$ ).

GQDs were characterized using including UV-vis, photoluminescence, FTIR and Raman spectroscopy and XRD analysis [10]. Size analysis of colloidal GQDs was carried out using TEM-JEM-2100F at a voltage of $200 \mathrm{kV}$. The samples were 
prepared by mounting a drop of the aqueous suspension containing the GQDs on a carbon grid, which then was placed on filter paper to absorb excess solvent. The average particle diameter and size distribution were calculated using Java Image tool software, based on the data of an average of 70-100 particles.

\section{Cytotoxicity on Breast Cancer Cells}

Human breast cancer cell line (MCF-7 strain) was purchased from National Centre for Cell Sciences (NCCS, Pune, India). The cells were maintained in DMEM with $10 \%$ fetal bovine serum, $1 \%$ penicillin and $0.5 \%$ streptomycin. The cultured cells were cultured at $37{ }^{\circ} \mathrm{C}$ in a $5 \% \mathrm{CO}_{2}$ humidified incubator.

Cell proliferation was monitored by 3-(4,5-dimethylthiazol-2-yl)- 2,5-di-phenyltetrazolium bromide (MTT) assay, as described by Mosmann [39], with slight modification by Murugan et al. [40]. Exponentially growing MCF 7 cells $\left(1 \times 10^{4}\right.$ cells per $\mathrm{mL}$ ) were seeded in 96-well plates in a final volume of $100 \mathrm{~mL}$ per well and treated with series $\left(1-50 \mathrm{mg} \mathrm{ml}^{-1}\right.$ ) of test samples (GQDs) in FCS free complete medium for $48 \mathrm{~h}$. $100 \mathrm{~mL}$ of MTT $\left(5 \mathrm{mg} \mathrm{ml}^{-1}\right)$ were added to treated cells, and the plates were incubated at $37{ }^{\circ} \mathrm{C}$ for $4 \mathrm{~h}$. The supernatant was aspirated and $100 \mathrm{~mL}$ of DMSO was added to each well to dissolve the formosan crystals. Absorbance was measured at $620 \mathrm{~nm}$ using a 96-well microplate reader (Lambda 1050 Perkin Elmer) and the inhibitory concentration $\left(\mathrm{IC}_{50}\right)$ was was calculated. The percentage of cell survival was calculated using the following formula: [41]:

Relative cell survival $(\%)=($ mean experimental cell absorbance $($ A620)/

$$
\text { mean control cell absorbance }(\mathrm{A} 620)) \times 100
$$

Flow cytometry was used to detect apoptotic cells with diminished DNA content [42]. MCF-7 cells were seeded into 6 -well plates at $1 \times 10^{5}$ cells/well. Posttreatment with GQDs, the cells were fixed in ice-cold $70 \%$ ethanol at $-20{ }^{\circ} \mathrm{C}$ overnight. After centrifugation and washing one time with PBS, low-molecularweight DNA was extracted using $0.2 \mathrm{~mol} / \mathrm{L}$ phosphate-citrate buffer and stained with $200 \mu \mathrm{L}$ of $1 \mathrm{mg} / \mathrm{mL}$ propidium iodine $(\mathrm{PI}) / 10 \mathrm{~mL}$, and $0.1 \%$ Triton $\mathrm{X}-100 /$ $2 \mathrm{mg}$ DNase-free RNase A. The solution was incubated for $30 \mathrm{~min}$ at room temperature in the dark, followed by flow cytometric analysis at $488 \mathrm{~nm}$ (BD, Franklin Lakes, NJ, USA).

\section{Hemolysis on Red Blood Cells}

Hemolysis activity was evaluated on the blood of one healthy donor (from Bharathiar University, Coimbatore, India). $5 \mathrm{~mL}$ of whole blood sample was added to $10 \mathrm{~mL}$ of $\mathrm{Ca}$ - and Mg-free Dulbecco's phosphate buffered saline (Sigma-Aldrich, USA) and centrifuged at $500 \mathrm{~g}$ for $10 \mathrm{~min}$ to isolate red blood cells (RBCs) from the serum. This purification was repeated five times, and then the washed RBCs were diluted to $50 \mathrm{~mL}$ in PBS. 1, 5, 10, 15, 20, $25 \mu \mathrm{L}$ of grapheme oxide suspended in tyrode, tyrode (negative control) or triton X-100 (positive control) were added to 5 $\mu \mathrm{L}$ of washed $\mathrm{RBC}$ suspension. The suspension was incubated at room temperature 
on a shaking plate for 1,4 and $24 \mathrm{~h}$. After the incubation time, the suspension was centrifuged at $10000 \mathrm{~g}$ over $5 \mathrm{~min}$. Supernatant was read on a 96-well plate using a microplate scanning spectrophotometer XMark (Lambda 1050 Perkin Elmer) at $550 \mathrm{~nm}$. The hemolysis (\%) was calculated as:

$$
\begin{gathered}
\mathrm{H}(\%)=(\text { OD550nm sample }- \text { OD550nm tyrode }) /(\text { OD550nm Triton } \mathrm{X}-1001 \% \\
- \text { OD550nm tyrode }) \times 100
\end{gathered}
$$

\section{Anopheles stephensi Rearing}

Following the method by Murugan et al. [43], eggs of $A$. stephensi were provided by the National Centre for Disease Control (NCDC) field station of Mettupalayam (Tamil $\mathrm{Nadu}$, India). For both species, eggs were transferred to laboratory conditions [27 $\pm 2{ }^{\circ} \mathrm{C}, 75-85 \%$ R.H., 14:10 (L:D) photoperiod] and placed in $18 \times 13 \times 4 \mathrm{~cm}$ plastic containers containing $500 \mathrm{~mL}$ of tap water, waiting for larval hatching $[44,45]$. Larvae were reared in the containers and fed daily with a mixture of crushed dog biscuits (Pedigree, USA) and hydrolyzed yeast (Sigma-Aldrich, Germany) at a 3:1 ratio (w:w). Water was renewed every two days. The breeding medium was checked daily and dead individuals were removed. Breeding containers were kept closed with muslin cloth to prevent contamination by foreign mosquitoes. Pupae were collected daily from culture containers and transferred to glass beakers containing $500 \mathrm{~mL}$ of water. Each glass beaker contained about 50 mosquito pupae and was placed in a mosquito-rearing cage $(90 \times 90 \times 90 \mathrm{~cm}$, plastic frames with chiffon walls $)$ until adult emergence. Mosquito adults were continuously provided with $10 \%$ (w:v) glucose solution on cotton wicks. The cotton was always kept moist with the solution and changed daily. Five days after emergence, females were supplied with a blood meal which was furnished by means of professional heating blood (lamb blood), at a fixed temperature of $38{ }^{\circ} \mathrm{C}$ and enclosed in a membrane of cow gut. After $30 \mathrm{~min}$, the blood meal was removed and a fresh one was introduced [43].

\section{Acute Toxicity on Anopheles stephensi}

Twenty-five A. stephensi larvae (I, II, III and IV instar) or pupae were placed for $24 \mathrm{~h}$ in a glass beaker filled with $250 \mathrm{~mL}$ of dechlorinated water in a $500 \mathrm{~mL}$ glass beaker, and $1 \mathrm{~mL}$ of the desired concentration of GQD was added and replicated for five times against all instars. Larval food $(0.5 \mathrm{mg})$ was provided for each tested concentration [44]. Control mosquitoes were exposed for $24 \mathrm{~h}$ to the corresponding concentration of the solvent. Percentage mortality was calculated as follows:

Percentage mortality $=$ (number of dead individuals $/$

$$
\text { number of treated individuals) } \times 100
$$




\section{In vitro Cultivation of Plasmodium falciparum}

Following the method by Murugan et al. [35], here a CQ-sensitive strain 3D7 and CQ-resistant strain INDO of $P$. falciparum were used in in vitro blood stage culture to test the anti-malarial efficacy of GQDs. The culture was carried out at G. Kuppusamy Naidu Memorial Hospital (Coimbatore, India). P. falciparum culture was maintained according to the method described by Trager and Jensen [46], with minor modifications. P. falciparum (3D7) cultures were maintained in fresh $\mathrm{O}^{+\mathrm{ve}}$ human erythrocytes suspended at $4 \%$ hematocrit in RPMI 1640, containing $0.2 \%$ sodium bicarbonate, $0.5 \%$ albumax, $45 \mu \mathrm{g} / \mathrm{L}$ hypoxanthine and $50 \mu \mathrm{g} / \mathrm{L}$ gentamycin and incubated at $37{ }^{\circ} \mathrm{C}$ under a gas mixture of $5 \% \mathrm{O}_{2}, 5 \% \mathrm{CO}_{2}$ and $90 \%$ $\mathrm{N}_{2}$. Every day, infected erythrocytes were transferred into a fresh complete medium to propagate the culture. For $P$. falciparum (INDO strain) in culture medium, albumax was replaced by $10 \%$ pooled human serum.

\section{In vitro Antiplasmodial Activity}

Control stock solutions of CQ were prepared in water (milli-Q grade); the tested GQDs were prepared in dimethyl sulfoxide (DMSO). All stocks were diluted with culture medium to achieve the required concentrations (in all cases except $\mathrm{CQ}$, the final solution contained $0.4 \%$ DMSO, which was found to be non-toxic to the parasite). Then, GQDs were placed in 96-well flat-bottom tissue culture-grade plates.

GQDs were evaluated for anti-malarial activity against $P$. falciparum strains 3D7 and INDO. For drug screening, SYBR green I-based fluorescence assay was used following the method by Smilkstein et al. [47]. Sorbitol-synchronized parasites were incubated under normal culture conditions at $2 \%$ hematocrit and $1 \%$ parasitemia in the absence or presence of increasing concentrations of samples, where CQ was used as positive control. After $48 \mathrm{~h}$ of incubation, $100 \mu \mathrm{L}$ of SYBR Green I solution $\{0.2 \mu \mathrm{L}$ of $10000 \mathrm{X}$ SYBR Green I (In vitrogen)/mL $\}$ in lysis buffer [Tris $(20 \mathrm{mM}$; pH 7.5), EDTA (5 mM), saponin (0.008\%; w/v) and Triton X-100 (0.08\%; v/v)] was added to each well and mixed gently twice with a multi-channel pipette and incubated in the dark at $37{ }^{\circ} \mathrm{C}$ for $1 \mathrm{~h}$. Fluorescence was measured with a Victor fluorescence multi-well plate reader (Perkin Elmer) with excitation and emission wavelength bands centered at 485 and $530 \mathrm{~nm}$, respectively. The fluorescence counts were plotted against the drug concentration and the $50 \%$ inhibitory concentration $\left(\mathrm{IC}_{50}\right)$ was determined by an analysis of dose-response curves. Results were validated microscopically by the examination of Giemsa-stained smears of extract-treated parasite cultures [48, 35].

\section{In vivo Antiplasmodial Activity}

Following the method by Rajakumar et al. [49] and Murugan et al. [50], male albino mice (weight: 27-30 g) were tested; the animal were fed ad libitum with standard mouse cubes (Barastoc) and clean drinking water. Animals were sexed and caged in groups of five. The animals were housed in the Animal House in Kovai Medical 
Centre and Hospital, College of Pharmacy, Coimbatore. Experiments were performed following the Peters' 4-day curative standard test [51-53]. For each bioassay, three albino mice were used to test the antimalarial potential of GQDs. Chloroquine-treated (Sigma-Aldrich) and untreated control groups of mice were tested separately as positive and negative controls [50]. The GQDs were orally administered to the test groups of mice infected by Plasmodium berghei at different dose levels, from 0 to 4 days. Chloroquine was used as a standard drug with normal saline $(0.9 \%)$ at $5(\mathrm{mg} / \mathrm{kg})$ was used as positive and the negative control group received distilled water $(1 \mathrm{~mL})$.

Parasitemia was monitored in all the groups starting from 0 to 4 days using thin smears of blood films made from the tail vein of the mice [54]. After incubation for $24 \mathrm{~h}$, Giemsa-stained thin blood films were prepared for each mice, and the percentage of inhibition of parasite growth was determined under a microscope. The percent inhibition at each concentration was determined. The percentage of chemosuppression of the total parasitemia for each dose was calculated as: $[(\mathrm{A}-\mathrm{B} /$ A] $\times 100$ as described by Argotte et al. [55], where A is the mean parasitemia in the untreated control group and B is the parasitemia in each experimental group. Animals from the treated and control groups were followed up until the end of the experiment (10 days after being infected), and the blood samples were taken from all the experimental animals to estimate parasitemia [50].

\section{Impact on Non-target Mosquito Predators}

Here, the predation efficiency of mosquitofish $G$. affinis, dragonfly nymph $A$. immaculifrons, Indian bullfrog $H$. tigerinus was assessed against $A$. stephensi larvae. Following the method by Murugan et al. [56], for each instar, 200 mosquitoes were introduced, with an adult fish, a dragonfly nymph or a tadpole in a 500-mL glass beaker containing $250 \mathrm{~mL}$ of dechlorinated water. Mosquito larvae were replaced daily with new ones. For each mosquito instar, five replicates were conducted. Control was $250 \mathrm{~mL}$ of dechlorinated water without predators. All beakers were checked after 12 and $24 \mathrm{~h}$, and the number of missing preys, assumed as eaten by the predator, was recorded. Missing mosquito larvae were replaced after each daily check with new ones. Predation efficiency was calculated using the following formula:

Predatory efficiency $=$ (number of consumed mosquitoes/number of predators $)$ total number of mosquitoes $\times 100$.

Furthermore, the predation efficiency of $G$. affinis, dragonfly nymphs $A$. immaculifrons and Indian bullfrogs $H$. tigerinus was also evaluated post-treatment with ultra-low doses of GQDs. For each instar, 200 mosquitoes were introduced with 1 fish, 1 dragonfly nymph or 1 tadpole in a 500-mL glass beaker filled with $250 \mathrm{~mL}$ of dechlorinated water plus the desired concentration of GQDs (i.e. 1/3 of the $\mathrm{LC}_{50}$ calculated against the tested larval instar of A. stephensi, [57]. Mosquito larvae were replaced daily with new ones. For each mosquito instar, five replicates 
were conducted. Control was dechlorinated water without predators. All beakers were checked after 12 and $24 \mathrm{~h}$ and the number of prey consumed by each predator species was recorded. Then, the predation efficiency of each mosquito natural enemy was calculated using the above-mentioned formula.

\section{Data Analysis}

SPSS software package 16.0 version was used for all analyses. Data from larvicidal and pupicidal experiments were analyzed by probit analysis, calculating $\mathrm{LC}_{50}$ and $\mathrm{LC}_{90}$ [58]. Similarly, concerning in vitro antiplasmodial assays, the GQDs and chloroquine concentrations causing $50 \%$ inhibition of parasite growth $\left(\mathrm{IC}_{50}\right)$ were calculated from the drug concentration-response curves. As regard to in vivo antiplasmodial assays, all values are expressed as percentage growth inhibition. Inhibition data were transformed into arcsine $\sqrt{ }$ proportion values, and analyzed using ANOVA with two factors (i.e. tested drug and dose). Means were separated using Tukey's HSD test $(\mathrm{P}<0.05)$.

\section{Results and Discussion}

\section{Characterization of Graphene Quantum Dots}

GQD were synthesized following the modified method by Hummers where an orange yellow solution was obtained in photo-Fenton reaction of graphene oxide [59]. Graphene with $50 \mathrm{wt} \% \mathrm{KMnO}_{4}$ was successfully sheared as tiny dots by acidic suspension and the excess of $\mathrm{KMnO}_{4}$ was consumed by hydrothermal process. Finally, a deep yellow solution dialyzed to get the final product of greenish fluorescent GQDs was freeze-dried and used for further assays. The synthetic process is cheap and relatively simple without the help of strong acid to cut large graphene oxide. Furthemore, the synthesis was in aqueous solution and the product yield is about $34.8 \%$ in weight, higher than the other reported GQD synthesis routes $[8,60]$.

The purified GQDs were characterized using biophysical techniques including UV-vis, photoluminescence, FTIR and Raman spectroscopy, XRD analysis and TEM, which confirmed the effective nanosynthesis of GQDs (Fig. 1). UV-vis and PL spectra of the nanosynthesized GQDs were shown in Fig. 1a and b. The UV-vis spectrum showed two sharp peaks at 285 and $325 \mathrm{~nm}$ by emits bright green fluorescence when irradiated by a UV light, which was assigned to $\pi-\pi^{*}$ absorption peak at $285 \mathrm{~nm}$, a new absorption band at $325 \mathrm{~nm}$ was similar with the results by Fan et al. [61]. The UV spectrum of graphene is also affected on reduction, wherein the intensity of the maximum band decreases progressively, with a new long tail band appeared at higher wavelength [62]. Similarly, the PL spectrum (Fig. 1b) exhibited a peak at $505 \mathrm{~nm}$. This excitation-independent PL behavior is different from most of the reported carbon-based nanomaterials [63, 64], which were dependent on excitation wavelength and always shifted to longer wavelengths. This 

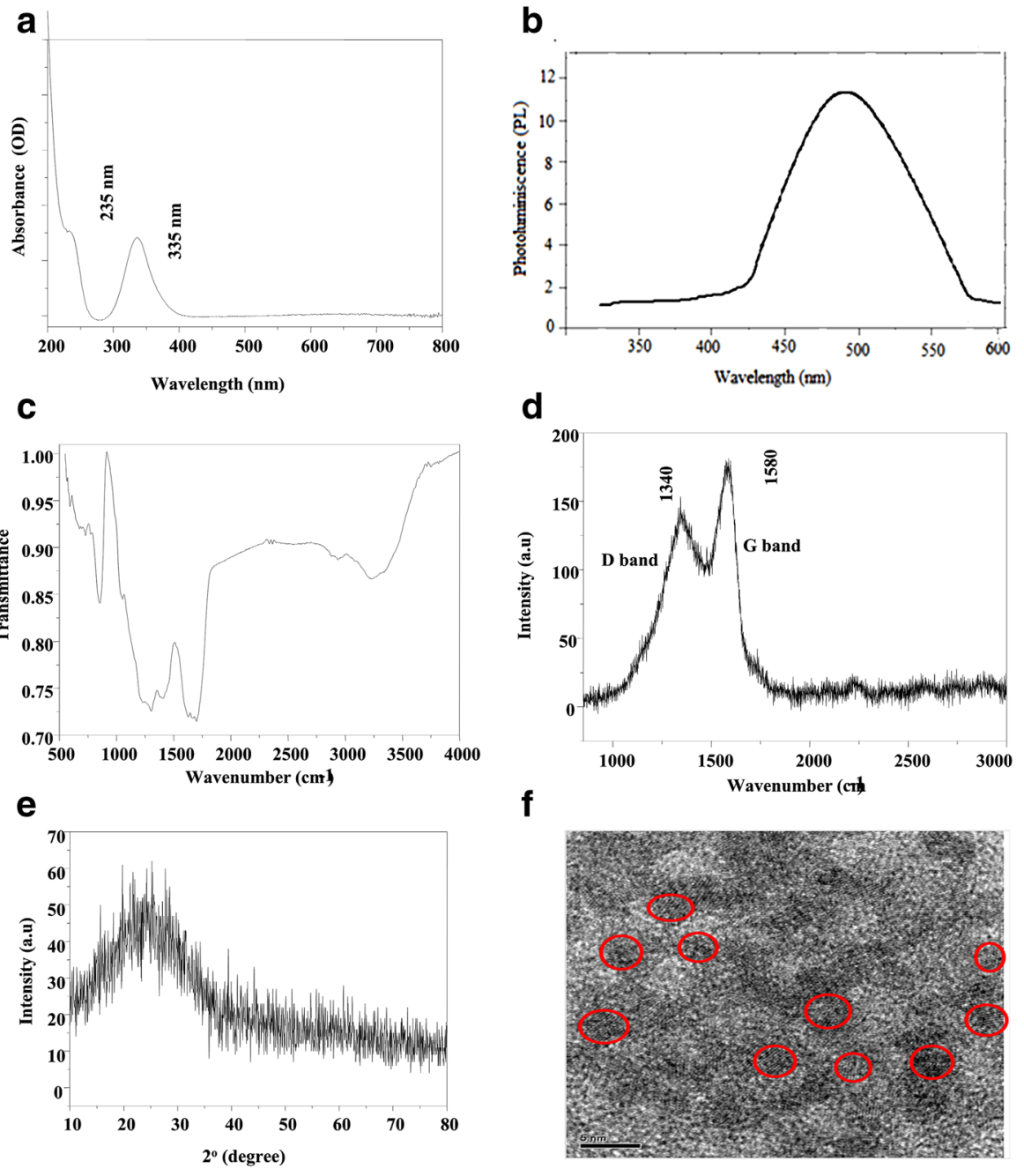

Fig. 1 Biophysical characterization of nanofabricated graphene quantum dots: a UV-visible spectrum; b photoluminescence (PL) spectrum at $505 \mathrm{~nm}$; c functional group prediction by FTIR spectroscopy; d Raman spectrum; e XRD analysis; f TEM

special feature may result from less surface defects and more uniform size of GQDs [65].

The GQDs synthesized here were characterized for their functional groups by FTIR spectroscopy, as reported by Fig. 1c. The carboxyl and hydroxyl groups were absorbed, where the stretching vibrations of $\mathrm{OH}$ was intense showing a broad band at $3235-\mathrm{OH} \mathrm{cm} \mathrm{cm}^{-1}$ and carboxylic acid stretching vibration ranged at $1200-1400 \mathrm{~cm}^{-1}$. The stretching vibration at $1688 \mathrm{~cm}^{-1}$ may be due to $\mathrm{C}=\mathrm{C}$. The presence of aromatic groups from proteins and peptides was confirmed by the presence of carbonyl $(\mathrm{C}=\mathrm{O})$ stretching vibration at $1613 \mathrm{~cm}^{-1}$ from the amide 
functional groups [10]. $850 \mathrm{~cm}^{-1}$ probably correspond to out of plane C-H vibration. These FTIR spectrum at various stretching vibration showed that the dispersion of GQDs nanocomposite into aqueous medium was in accordance with Wang et al. [66].

The effective synthesis of GQDs was confirmed by Raman spectrum (Fig. 1d). Intense Raman D bands were observed at $1340 \mathrm{~cm}^{1}$ and $\mathrm{G}$ band at $1580 \mathrm{~cm}^{1}$. These bands are similar to those reported for high quality few-layer graphene nanoribbons [67]. The unique small ratio indicates fewer defects of the GQDs developed by chemical oxidation and exfoliation method over those synthesized by other methods [68]. The XRD pattern of GQDs represented in Fig. 1e predicted the board peak at diffraction plane (002), centered at around 24.12; the interlayer d spacing was found to be $0.36 \mathrm{~nm}$, which is broader than that of graphite [69]. TEM of GQDs was reported in Fig. 1f, showing evenly distributed uniform size of tiny GQDs at 4-5 nm, in good agreement to the $5 \mathrm{~nm}$-GQDs synthesized by cutting graphene oxide sheets as reported using the Hummers method slightly modified by Fan et al. [61].

\section{Cytotoxicity of Graphene Quantum Dots on Breast Cancer Cells}

The MTT assay was performed to assess the in vitro cytotoxicity of GQDs against human breast carcinoma (MCF-7) cell lines. GQDs exerted cytotoxicity on MCF-7 cells in a dose-dependent manner (Fig. 2a). The $\mathrm{IC}_{50}$ value of GQDs was $24.81 \mu \mathrm{g} /$ $\mathrm{mL}$ after $48 \mathrm{~h}$ from the treatment. Nanosynthesized GQDs could be quickly internalized into the cells interacting with the functional groups of intracellular proteins as well as with the nitrogen bases and phosphate groups in DNA. This interaction helps GQDs to decrease the cell viability by alterations in the nuclear morphology, cytoplasm organization, and changes in gene expression of MCF-7 cells. Nitrogen-doped GQDs were co-cultured with HeLa cells and did not showed considerable toxicity on HeLa cells by 3-(4, 5-dimeth-ylthiazol-2-yl)-2, 5-diphenyl tetrazolium bromide test (MTT) assay [60], see also [70]. To our mind, GQDs are a possible candidate to inhibit tumor progression and thereby effectively controlling the disease progression without toxicity towards normal cells.

Apoptosis is an important regulatory pathway of cell growth and proliferation in which cells respond to specific induction signals by initiating intracellular processes that result in characteristic physiological changes occurring over few hours [71]. Using flow cytometry at $488 \mathrm{~nm}$, the apoptotic cells were separated from normal cells, exploiting their reduced DNA content. The induction of apoptosis was higher in GQDs-treated cells post-exposure to the doses of 1.88, 3.75, 7.5, 1.5 and $30 \mu \mathrm{g} /$ $\mathrm{mL}$. In agreement with Jaganathan et al. [42], the apoptotic percentage of MCF-7 cells increased significantly $(\mathrm{P}<0.001)$ with the GQD tested dose (i.e. from 1.9 to $8.4 \%$ ) (Fig. 2b). Results suggested that GQDs are able to trigger Bax/Bcl2/cytochrome c/caspase-3 signaling pathway, activating apoptosis of MCF-7 cells (see also [42]). 

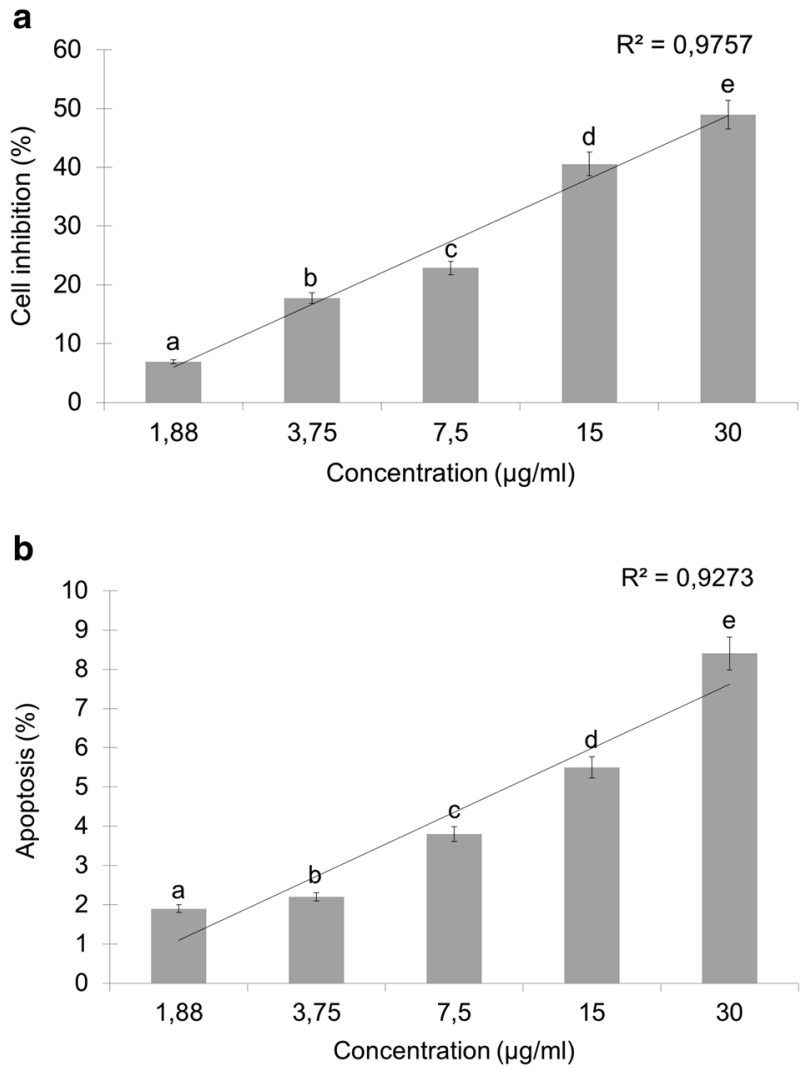

Fig. 2 Toxicity of graphene quantum dots against MCF-7 cancer cell lines: a cell growth inhibition (\%); b graphene quantum dots-triggered cell apoptosis, monitored using flow cytometry at $488 \mathrm{~nm}$. Above each column, different letters indicate significant differences among treatments (ANOVA, Tukey's HSD test, $\mathrm{P}<0.05)$

\section{Hemolytic Activity}

The extent of hemolysis in malaria is greater if compared to other parasites inducing hemolytic states. Here in vitro blood companionable of GQDs was assessed as hemolytic activity from the whole blood of healthy adult volunteers. The absorbance spectrum of the supernatant of RBC suspension $0.5 \%(\mathrm{v} / \mathrm{v})$ incubated with Triton X-100 $1 \%(\mathrm{v} / \mathrm{v})$ and negative control tyrode was measured at wavelength of $550 \mathrm{~nm}$ and the percentage of hemolytic was given in Fig. 3. It was noted that GQDs should be tested at rather high doses (i.e. 1, 5, 10, 15, 20 and $25 \mu \mathrm{g}$ ) to induce hemolytic activity (i.e. 3.26, 10.7, 40, 60.92 and $80.95 \%$, respecitvely). This activity may be due the action of GQDs on the RBC membrane, if compared to the positive control (1\% Triton X-100) and negative control (tyrode). The binding of GQDs to the RBC molecule can be linked to the small particle size of GQDs which is also linked to the strong electrostatic interactions with phosphatidylcholine lipids present on the surface of the RBC membrane [72]. 


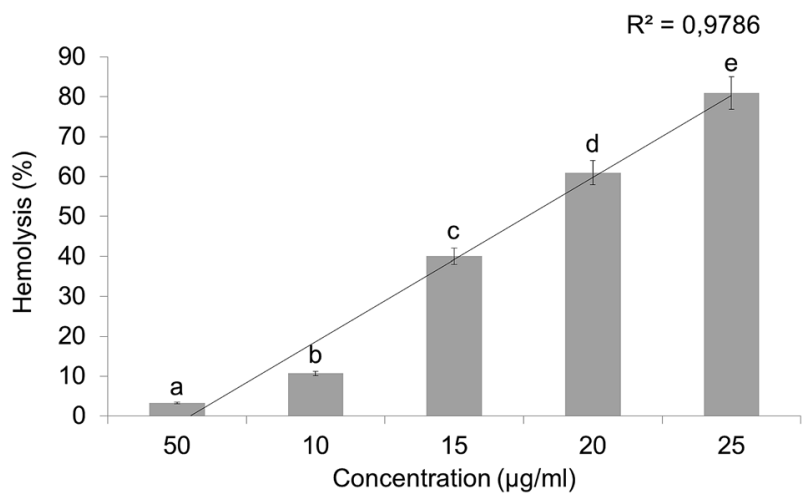

Fig. 3 Hemolysis induced in red blood cells incubated with different concentrations of graphene quantum dots. Above each column, different letters indicate significant differences among treatments (ANOVA, Tukey's HSD test, $\mathrm{P}<0.05$ )

In agreement with our findings, the size-dependent cytotoxicity on human RBCs and mammalian cells has been reported earlier testing other nanoparticles, such as silica [73, 74] and latex ones [75]. In addition, studies on hemolytic activity of silver nanoparticles showed that the release of low silver ion concentrations leads to the death of RBC molecule [76]. In this scenario, from our results of hemolytic activity assays, we believe that GQDs could represent a better candidate in preventing the destruction of RBC membrane induced by malarial parasites, if compared to metal nanoparticles.

\section{Mosquitocidal and Antiplasmodial Potential}

GQDs were toxic against larvae and pupae of the malaria vector A. stephensi. $\mathrm{LC}_{50}$ values were 0.157 (larva I), $2.756 \mathrm{ppm}$ (II), $3.055 \mathrm{ppm}$ (III), $4.884 \mathrm{ppm}$ (IV) and $6.323 \mathrm{ppm}$ (pupa) (Table 1) respectively. In latest years, a growing number of nanocomposites have been studied for their toxic activity against young instars of several mosquito vectors (e.g. [11, 25, 36, 37, 44, 45, 77-80]). A good example is the larvicidal activity of Sargassum muticum-synthesized Ag nanoparticles against larval instars and pupae of A. aegypti, A. stephensi, and C. quinquefasciatus [81]. Recently, Subramaniam et al. [82] highlighted that low doses of Au nanoparticles synthesized using flower extract of Corocoupita guianensis are highly toxic to $A$. stephensi larvae and pupae, with $\mathrm{LC}_{50}$ of $17.36 \mathrm{ppm}$ (I), $19.79 \mathrm{ppm}$ (II), $21.69 \mathrm{ppm}$ (III), 24.57 ppm (IV), and 28.78 ppm (pupae), respectively. However, despite these interesting evidences, limited efforts are still available on the precise mechanism(s) of action of nanoparticles against mosquitoes [25].

In the in vitro antiplasmodial assays, GQDs showed high activity against $P$. falciparum if compared to CQ. Indeed, GQDs $\mathrm{IC}_{50}$ were $82.43 \mu \mathrm{g} / \mathrm{mL}$ (CQ-s) and $85.17 \mu \mathrm{g} / \mathrm{mL}$ (CQ-r), while $\mathrm{IC}_{50}$ of CQ were $90 \mu \mathrm{g} / \mathrm{mL}$ (CQ-s) and $95 \mu \mathrm{g} / \mathrm{mL}$ (CQr) (Fig. 4). In agreement with these results, Murugan et al. [35] recently pointed out the high antiplasmodial activity of Ag nanoparticles fabricated using a non-toxic and cheap aqueous extract of the seaweed Ulva lactuca on P. falciparum. $\mathrm{IC}_{50}$ were 
Table 1 Acute toxicity of nanofabricated graphene quantum dots on young instars of the malaria vector Anopheles stephensi

\begin{tabular}{llllll}
\hline Target & $\mathrm{LC}_{50}\left(\mathrm{LC}_{90}\right)$ & \multicolumn{2}{l}{$95 \%$ Confidence limit LC $\mathrm{LC}_{50}\left(\mathrm{LC}_{90}\right)$} & Regression equation & $\begin{array}{l}\chi^{2} \\
(d . f .=4)\end{array}$ \\
\cline { 3 - 5 } & & Lower & Upper & & \\
\hline Larva I & $0.157(7.361)$ & $0.157(6.599)$ & $2.35(8.460)$ & $y=0.322+0.218 x$ & $5.11 \mathrm{n} . \mathrm{s}$ \\
Larva II & $2.756(8.508)$ & $1.831(7.704)$ & $3.437(9.660)$ & $y=0.614+0.223 x$ & $2.512 \mathrm{n} . \mathrm{s}$ \\
Larva III & $3.055(10.593)$ & $1.763(8.971)$ & $3.875(13.773)$ & $y=0.519+0.170 x$ & $0.736 \mathrm{n} . \mathrm{s}$ \\
Larva IV & $4.884(13.520)$ & $3.952(11.716)$ & $5.653(16.615)$ & $y=0.725+0.148 x$ & $0.975 \mathrm{n} . \mathrm{s}$ \\
Pupa & $6.323(13.994)$ & $5.643(12.293)$ & $7.064(16.748)$ & $y=1.060+0.167 x$ & 0.807 n.s \\
\hline
\end{tabular}

No mortality was observed in the control

$L C_{50}$ lethal concentration that kills $50 \%$ of the exposed organisms

$L C_{90}$ lethal concentration that kills $90 \%$ of the exposed organisms

$\chi^{2}$ Chi square value

d.f. degrees of freedom

n.s. not significant $(\alpha=0.05)$

$76.33 \mu \mathrm{g} / \mathrm{mL}$ (CQ-s) and $79.13 \mu \mathrm{g} / \mathrm{mL}$ (CQ-r). In addition, Murugan et al. [50] also showed that even neem seed kernel-synthesized $\mathrm{Ag}$ nanoparticles achieved comparable $\mathrm{IC}_{50}$ on $P$. falciparum, i.e. $82.41 \mu \mathrm{g} / \mathrm{mL}$ (CQ-s) and $86.12 \mu \mathrm{g} / \mathrm{mL}$ (CQ-r). As recently summarized by Benelli [25], the antiplasmodial effectiveness of the above-mentioned nano formulations may due the inhibition of Plasmodium merozoite invasion into erythrocytes. However, further studies on these potential mechanisms are needed.

In vivo antiplasmodial experiments highlighted that, after being inoculated intraperitoneally with $1 \times 10^{7} \mathrm{P}$. berghei infected RBCs, the untreated control showed progressively increasing parasitemia. Peters' 4-day chemo suppressive activity tests conducted with GQDs showed dose-dependent chemo suppression

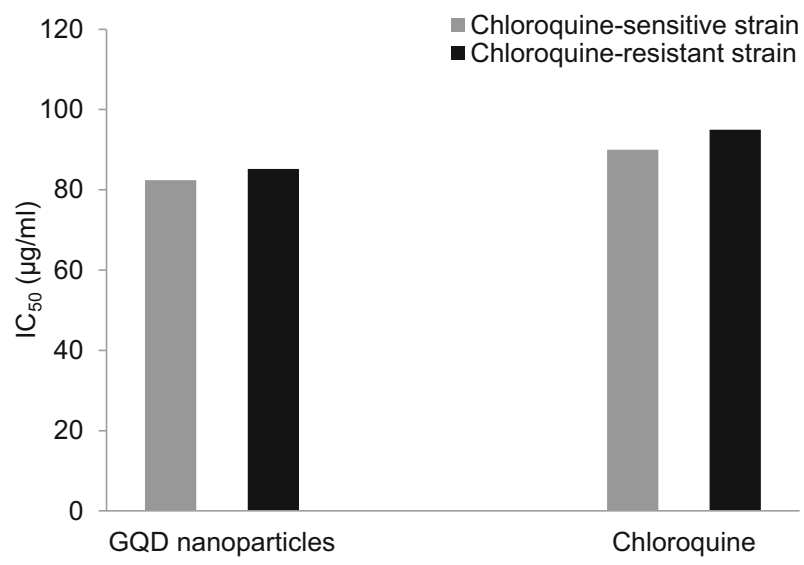

Fig. 4 In vitro growth inhibition of chloroquine-sensitive and chloroquine-resistant strains of $P$. falciparum post-treatment with graphene quantum dots (GQD) and chloroquine 
Table 2 In vivo growth inhibition of Plasmodium berghei parasites infecting albino mice post-treatment with graphene quantum dots or chloroquine

\begin{tabular}{lllr}
\hline Treatment & $\begin{array}{l}\text { Dose }(\mathrm{mg} / \\
\text { kg/day) }\end{array}$ & $\begin{array}{l}\text { Suppression of parasitemia at day } \\
(\%)\end{array}$ & $\begin{array}{l}\text { Chemosuppression } \\
(\%)\end{array}$ \\
\hline $\begin{array}{l}\text { Graphene quantum } \\
\text { dots }\end{array}$ & 5 & $58.9 \pm 0.6$ & $6.72 \pm 0.38^{\mathrm{b}}$ \\
& 10 & $52.8 \pm 0.21$ & $8.6 \pm 1.01^{\mathrm{bc}}$ \\
& 15 & $45.4 \pm 1.02$ & $9.4 \pm 1.02^{\mathrm{cd}}$ \\
& 20 & $26.4 \pm 0.8$ & $15.6 \pm 1.2^{\mathrm{d}}$ \\
& 25 & $23.6 \pm 1.01$ & $26.6 \pm 0.49^{\mathrm{e}}$ \\
Chloroquine & 30 & $14.8 \pm 1.33$ & $28.6 \pm 0.49^{\mathrm{f}}$ \\
Distilled water & 5 & $1.0 \pm 0.00$ & $100 \pm 0.00^{\mathrm{g}}$ \\
\hline
\end{tabular}

(Table 2). After four days from the treatment with GQDs, the mean parasitemia (\%) of the test groups ranged from $14.8 \pm 1.33$ to $58.9 \pm 0.6$ respectively (Table 2). Similarly, Rajakumar et al. [49] showed that dose-dependent suppression of parasitemia triggered by Eclipta prostrata-synthesized palladium nanoparticles on $P$. berghei in Swiss albino mice. In our assays, the highest suppression of parasitemia was observed at the dose of $30 \mathrm{mg} / \mathrm{kg} /$ day in albino mice, while only $5 \mathrm{mg} / \mathrm{kg} /$ day of CQ were needed to completely suppress $P$. berghei. In agreement with Murugan et al. [50], this pointed out the crucial importance of in vivo tests, which should always follow in vitro screenings, since in vivo effectiveness often differs from promising in vitro results. To the best of our knowledge, this is the first in in vivo evaluation of the effectiveness of GQDs on malaria parasites.

\section{Impact on Non-Target Mosquito Predators}

Here, we studied the impact of GQDs on the predation activity of adults of the mosquito fish G. affinis, nymphs of the dragonfly A. immaculifrons, and tadpoles of the Indian bullfrogs $H$. tigerinus against Anopheles stephensi young instars. In standard laboratory conditions, G. affins, A. immaculifrons, and H. tigerinus actively predated on A. stephensi (Table 3). Predation efficiency towards A. stephensi was $68.2 \%$ (larva II) $58.35 \%$ (larva III) for G. affinis, $53.9 \%$ (larva II) and $48.65 \%$ (larva III) for A. immaculifrons, and $53 \%$ (larva II) and $41.35 \%$ (larva III) for $H$. tigerinus. In agreement with our data, G. affinis has been recently reported as a more efficient predator of mosquito young instars if compared to other aquatic organisms, such as Belostomatidae and odonate nymphs [83]. However, Bowatte et al. [84] also highlighted the role of Bufo, Euphlyctis, Hoplobatrachus, Polypedates, and Ramanella tadpoles in reducing mosquito populations through predation on mosquito eggs.

Notably, post-treatment with GQDs, the predation efficiency were boosted to $96.5 \%$ (larva II) and $88.8 \%$ (larva III) for G. affinis, $88.1 \%$ (larva II) and $81.6 \%$ (larva III) for A. immaculifrons, and $84.1 \%$ (larva II) and $75.15 \%$ (larva III) for $H$. tigerinus, respectively (Table 3 ). To the best of our knowledge, scarce information 
Table 3 Impact of nanofabricated graphene quantum dots (GQD) on the predation efficiency of three natural enemies of Anopheles stephensi young instars: the adults of larvivorous fish Gambusia affinis, the nymphs of dragonfly Anax immaculifrons, and the tadpoles of Asian bullfrog Hoplobatrachus tigerinus

\begin{tabular}{|c|c|c|c|c|c|}
\hline \multirow[t]{2}{*}{ Predator species } & \multirow[t]{2}{*}{ Treatment } & \multirow[t]{2}{*}{ Target } & \multicolumn{2}{|l|}{ Predation $(\%)$} & \multirow{2}{*}{$\begin{array}{l}\text { Mean } \\
\text { predation } \\
(\%)\end{array}$} \\
\hline & & & Daylight time & Night time & \\
\hline \multirow[t]{4}{*}{ G. affinis } & \multirow[t]{2}{*}{ Standard conditions } & Larva II & $72.0 \pm 1.0^{\mathrm{e}}$ & $64.5 \pm 1.2^{\mathrm{d}}$ & $68.2^{\mathrm{d}}$ \\
\hline & & Larva III & $60.6 \pm 0.8^{\mathrm{f}}$ & $56.1 \pm 1.1^{\mathrm{e}}$ & $58.35^{\mathrm{e}}$ \\
\hline & \multirow[t]{2}{*}{ Post-treatment with GQD ${ }^{\S}$} & Larva II & $97.5 \pm 1.1^{\mathrm{a}}$ & $95.8 \pm 1.1^{\mathrm{a}}$ & $96.5^{\mathrm{a}}$ \\
\hline & & Larva III & $91.1 \pm 1.0^{\mathrm{b}}$ & $86.5 \pm 1.3^{\mathrm{b}}$ & $88.8^{\mathrm{b}}$ \\
\hline \multirow[t]{4}{*}{ A. immaculifrons } & \multirow[t]{2}{*}{ Standard conditions } & Larva II & $56.3 \pm 1.5^{\mathrm{f}}$ & $51.5 \pm 1.3^{\mathrm{ef}}$ & $53.9^{\mathrm{e}}$ \\
\hline & & Larva III & $50.1 \pm 0.7^{\mathrm{g}}$ & $47.2 \pm 1.2^{\mathrm{f}}$ & $48.65^{\mathrm{f}}$ \\
\hline & \multirow[t]{2}{*}{ Post-treatment with GQD ${ }^{\S}$} & Larva II & $90.2 \pm 0.7^{\mathrm{b}}$ & $86.0 \pm 0.7^{\mathrm{b}}$ & $88.1^{\mathrm{b}}$ \\
\hline & & Larva III & $83.0 \pm 1.7^{\mathrm{c}}$ & $80.2 \pm 0.7^{\mathrm{bc}}$ & $81.6^{\mathrm{bc}}$ \\
\hline \multirow[t]{4}{*}{ H. tigerinus } & \multirow[t]{2}{*}{ Standard conditions } & Larva II & $56.9 \pm 2.1^{\mathrm{f}}$ & $49.1 \pm 1.0^{\mathrm{f}}$ & $53.0^{\mathrm{e}}$ \\
\hline & & Larva III & $42.6 \pm 1.6^{\mathrm{h}}$ & $40.1 \pm 1.1^{\mathrm{g}}$ & $41.35^{\mathrm{g}}$ \\
\hline & \multirow[t]{2}{*}{ Post-treatment with GQD ${ }^{\S}$} & Larva II & $87.9 \pm 1.7^{\mathrm{bc}}$ & $80.3 \pm 1.2^{\mathrm{bc}}$ & $84.1^{\mathrm{b}}$ \\
\hline & & Larva III & $78.4 \pm 1.6^{\mathrm{d}}$ & $71.9 \pm 1.6^{\mathrm{c}}$ & $75.15^{\mathrm{c}}$ \\
\hline
\end{tabular}

$\S$ see text for the tested dosage

Predation rates are mean \pm SD of five replicates (1 predator vs. 200 A. stephensi larvae per replicate) Control was clean water, without mosquito predators

Within each column, values followed by different letter(s) are significantly different (generalized linear model, $\mathrm{P}<0.05)$

is available about how ultra-low dosages of nanoparticles impact behavioral traits of aquatic organisms sharing the same ecological niche as mosquitoes [11, 25, 32-34, 36, 37, 82]. For instance, Subramaniam et al. [85] reported that Mimusops elengi-synthesized silver nanoparticles did not negatively impact predation rates of the mosquitofish G. affinis against A. stephensi and Aedes albopictus, validating this novel control tool in an environment-friendly perspective. As regards to carbon nanoparticles, Murugan et al. [10] have pointed out that a single treatment with $2 \mathrm{ppm}$ of carbon nanoparticles enhanced the predation efficiency of Lethocerus indicus against Culex quinquefasciatus larvae. As regards to genotoxicity, it has been showed that Carassius auratus erythrocytes showed no significant damages at carbon nanoparticle doses lower than 25 ppm [10].

\section{Conclusions}

Nowadays, the eco-friendly control of mosquitoes is a key challenge [86]. In this research we focused on the effectiveness of GQDs against $P$. falciparum, $P$. berghe $i$ and young instars of malaria mosquitoes. Notably, the predation efficiency of mosquito natural enemies $G$. affinis, A. immaculifrons and $H$. tigerinus posttreatment with an ultra-low dose of GQDs was boosted. In addition, GQDs were 
toxic against MCF-7 cancer cell lines with an $\mathrm{IC}_{50}=24.81 \mu \mathrm{g} / \mathrm{mL}$ and triggered apoptosis in 1.9-8.4\% of treated cells. Overall, this study highlighted the concrete potential of GQDs for the development of newer and safer drugs in the fight against Anopheles vectors, Plasmodium parasites and breast cancer cells. Extensive field assays based on the employ of GQDs against mosquito vectors are urgently required.

Acknowledgments Three anonymous reviewers improved an earlier version of this work. Dr. Anitha Jaganathan is grateful to the University Grant Commission (New Delhi, India), Project No. PDFSS-201415-SC-TAM-10125. Dr. Devakumar Dinesh would like to extend his sincere thanks for UGC (New Delhi, India) for granting RGNF-2015-17-SC-TAM-27906.

\section{Compliance with ethical standards}

Conflicts of Interest The Authors declare no competing interests.

\section{References}

1. N. Li, A. Than, X. Wang, S. Xu, L. Sun, H. Duan, C. Xu, and P. Chen (2016). ACS. Nano. 10, (3), 3622-3629. doi:10.1021/acsnano5b08103.

2. S. N. Baker and G. A. Baker (2010). Angew. Chemie. 49, (38), 6726-6744.

3. J. C. G. EstevesdaSilva and H. M. R. Goncalves (2011). Trends. Analyt. Chem. 30, (8), 1327-1336.

4. J. Shen, Y. Zhu, X. Yang, and C. Li (2012). Chem. Comm. 48, (31), 3686-3699.

5. W. H. De Jong and P. J. A. Borm (2008). Int. J. Nanomed. 3, (2), 133-149.

6. W. C. Lee, C. Haley, Y. X. Lim, H. Shi, A. Lena, L. Tang, Y. Wang, C. T. Lim, and K. P. Loh (2011). ACS. Nano. 5, (9), 7334-7341.

7. X. C. Yuan, Z. M. Liu, Z. Y. Guo, Y. H. Ji, M. Jin, and X. P. Wang (2014). Nanoscale. Res. Lett 9, 108.

8. D. Jiang, Y. Chen, N. Li, W. Li, Z. Wang, Jingli Zhu, H. Zhang, B. Liu, and S. Xu (2015). PLOS ONE 10, (12), e0144906.

9. M. Saxena, Sumit Kumar Sonkarb, and Sabyasachi Sarkar (2013). RSC. Adv. 3, 22504-22508.

10. K. Murugan, D. Nataraj, P. Madhiyazhagan, V. Sujitha, B. Chandramohan, C. Panneerselvam, D. Dinesh, R. Chandirasekar, K. Kovendan, U. Suresh, J. Subramaniam, M. Paulpandi, C. Vadivalagan, R. Rajaganesh, H. Wei, B. Syuhei, A. T. Aziz, M. Saleh Alsalhi, S. Devanesan, M. Nicoletti, A. Canale, and G. Benelli (2016). Parasitol. Res. 115, 1071-1083.

11. G. Benelli (2016). Parasitol. Res. 115, 23-34.

12. L. M. Rueda (2008). Dev Hydrobiol 595, (1), 477-487.

13. G. Benelli (2015). Parasitol. Res. 114, 2801-2805.

14. Mehlhorn H (ed) (2015) Encyclopedia of parasitology, 4th edn. Springer, New 893, York

15. G. Benelli (2016). Asia. Pacif. J. Trop. Biomed. 6, 353-354.

16. G. Benelli, A. Canale, A. Higuchi, K. Murugan, R. Pavela, and M. Nicoletti (2016). Asia. Pacif. J. Trop. Dis. 6, 253-258.

17. WHO (2016) Malaria Fact sheet, Updated January 2016

18. J. M. Cohen, D. L. Smith, C. Cotter, A. Ward, and G. Yamey (2012). Malaria. J. 11, 122.

19. G. Benelli and H. Mehlhorn (2016). Parasitol. Res. 115, 1747-1754.

20. V. Sharma, Rohini Samant, Ashit Hegde, and Khushrav Bhaja (2012). JAPI 60, 51-55.

21. G. Dhaliwal, P. A. Cornett, and L. M. Tierney (1979). Am. Fam. Physician. 69, 2599-2606.

22. S. Lehrer (2010). Med. Hypotheses. 74, 167-168.

23. S. Lehrer (2010). Anticancer. Res. 30, 1371-1373.

24. G. Benelli, A. Lo Iacono, A. Canale, and H. Mehlhorn (2016). Parasitol. Res. 115, 2131-2137.

25. G. Benelli (2016). Enzyme. Microbial. Technol.. doi:10.1016/j.enzmictec.2016.08.022.

26. A. F. Howard, G. Zhou, and F. X. Omlin (2007). BMC. Public. Health. 7, 199.

27. J. Hemingway and H. Ranson (2000). Annu. Rev. Entomol. 45, 371-391. 
28. K. Raghvendra (2002). ICMR Bull 32, (10), 1-7.

29. M. N. Naqqash, A. Gökçe, A. Bakhsh, and M. Salim (2016). Parasitol. Res. 115, 1363-1373.

30. C. D. Linde Physicochemical properties and environment fate of pesticides (Environmental Hazards Assessment Program, California, 1994). 9.

31. Lini K. Mathew (2016). Int. J. Adv Res. 4, (3), 1734-1739.

32. K. Murugan, D. Dinesh, M. Paulpandi, A. D. Althbyani, J. Subramaniam, P. Madhiyazhagan, L. Wang, U. Suresh, P. M. Kumar, J. Mohan, R. Rajaganesh, H. Wei, K. Kalimuthu, M. N. Parajulee, H. Mehlhorn, and G. Benelli (2015). Parasitol. Res. 114, 4349-4361.

33. K. Murugan, G. Benelli, C. Panneerselvam, J. Subramaniam, T. Jeyalalitha, D. Dinesh, M. Nicoletti, J. S. Hwang, U. Suresh, and P. Madhiyazhagan (2015). Exp. Parasitol. 153, 129-138.

34. K. Murugan, V. Priyanka, D. Dinesh, P. Madhiyazhagan, C. Panneerselvam, J. Subramaniam, U. Suresh, B. Chandramohan, M. Roni, M. Nicoletti, A. A. Alarfaj, A. Higuchi, M. A. Munusamy, H. F. Khater, R. H. Messing, and G. Benelli (2015). Parasitol. Res. 114, 3601-3610.

35. K. Murugan, C. M. Samidoss, C. Panneerselvam, A. Higuchi, M. Roni, U. Suresh, B. Chandramohan, J. Subramaniam, P. Madhiyazhagan, D. Dinesh, R. Rajaganesh, A. A. Alarfaj, M. Nicoletti, S. Kumar, H. Wei, A. Canale, H. Mehlhorn, and G. Benelli (2015). Parasitol. Res. 114, 4087-4097.

36. M. Govindarajan and G. Benelli (2016). Parasitol. Res.. doi:10.1007/s00436-015-4817-0.

37. M. Govindarajan and G. Benelli (2016). RSC Adv 6, 59021-59029.

38. W. S. Hummers and R. E. Offeman (1958). J. Am. Chem. Soc 80, 1339.

39. T. Mosmann (1983). J. Immunol. Methods. 65, 55-63.

40. K. Murugan, D. Dinesh, K. Kavithaa, M. Paulpandi, T. Ponraj, M. Saleh Alsalhi, S. Devanesan, J. Subramaniam, R. Rajaganesh, H. Wei, K. Suresh, M. Nicoletti, and G. Benelli (2016). Parasitol. Res. 115, 1085-1096.

41. A. Monks, D. Scudiero, P. Skehan, R. Shoemaker, K. Paull, D. Vistica, C. Hose, J. Langley, P. Cronise, A. Vaigro-Wolff, M. Gray-Goodrich, et al. (1991). J. Natl. Cancer. Inst. 83, 757-766.

42. A. Jaganathan, K. Murugan, C. Panneerselvam, P. Madhiyazhagan, D. Dinesh, C. Vadivalagan, Al Thabiani Aziz, B. Chandramohan, U. Suresh, R. Rajaganesh, J. Subramaniam, M. Nicoletti, A. Higuchi, A. A. Alarfaj, M. A. Munusamy, Suresh Kumar, and G. Benelli (2016). Parasitol. Int. 65, 276-284.

43. K. Murugan, M. Aamina Labeeba, C. Panneerselvam, D. Dinesh, U. Suresh, J. Subramaniam, P. Madhiyazhagan, J. S. Hwang, L. Wang, M. Nicoletti, and G. Benelli (2015). Res. Vet. Sci. 102, $127-135$.

44. D. Dinesh, K. Murugan, P. Madhiyazhagan, C. Panneerselvam, M. Nicoletti, W. Jiang, G. Benelli, B. Chandramohan, and U. Suresh (2015). Parasitol. Res. 14, 1519-1529.

45. U. Suresh, K. Murugan, G. Benelli, M. Nicoletti, D. R. Barnard, C. Panneerselvam, P. Mahesh Kumar, J. Subramaniam, D. Dinesh, and B. Chandramohan (2015). Parasitol. Res. 114, 1551-1562.

46. W. Trager and J. Jensen (1976). Science 193, 673-675.

47. M. Smilkstein, N. Sriwilaijaroen, J. X. Kelly, P. Wilairat, and M. Riscoe (2004). Antimicrob. Agents. Chemother. 48, 1803-1806.

48. E. Bensoussan, A. Nasereddin, F. Jonas, L. F. Schnur, and C. L. Jaffe (2006). J. Clin. Microbiol. 44, (4), 1435-1439.

49. G. Rajakumar, A. A. Rahuman, I. M. Chung, A. Vishnu Kirthi, S. Marimuthu, and K. Anbarasan (2015). Parasitol. Res. 114, 1397-1406.

50. K. Murugan, C. Panneerselvam, C. M. Samidoss, P. Madhiyazhagan, U. Suresh, M. Roni, B. Chandramohan, J. Subramaniam, D. Dinesh, R. Rajaganesh, M. Paulpandi, H. Wei, A. T. Aziz, M. Saleh Alsalhi, S. Devanesan, M. Nicoletti, R. Pavela, A. Canale, and G. Benelli (2016). Res. Vet. Sci. 106, 14-22.

51. W. Peters, J. H. Portus, and B. L. Robinson (1975). Ann. Trop. Med. Parasitol. 69, 155-171.

52. L. T. Peter and V. K. Anatoli, The Current Global Malaria Situation. Malaria: Parasite Biology, Pathogenesis and Protection. (ASM, Washington, 1998), pp. 11-22

53. A. F. David, J. R. Philip, R. C. Simon, B. Reto, and N. Solomon (2004). Nat. Rev. 3, 509-520.

54. A. C. Ene, S. E. Atawodi, D. A. Ameh, H. O. Kwanshie, and P. U. Agomo (2008). Trends. Med. Res. 3, (1), 16-23.

55. R. R. Argotte, A. G. Ramírez, G. M. C. Rodríguez, et al. (2006). J. Nat. Prod 69, 1442-1444.

56. K. Murugan, C. Panneerselvam, A. T. Aziz, J. Subramaniam, P. Madhiyazhagan, J. S. Hwang, Lan Wang, D. Dinesh, U. Suresh, M. Roni, A. Higuchi, M. Nicoletti, M. Saleh Alsalhi, and G. Benelli (2016). Environ. Sci. Poll. Res.. doi:10.1007/s11356-016-6832-9. 
57. K. Murugan, J. Anitha, D. Dinesh, U. Suresh, R. Rajaganesh, B. Chandramohan, J. Subramaniam, M. Paulpandi, C. Vadivalagan, P. Amuthavalli, L. Wang, J. S. Hwang, H. Wei, M. S. Alsalhi, S. Devanesan, S. Kumar, K. Pugazhendy, A. Higuchi, M. Nicoletti, and G. Benelli (2016). Ecotoxicol. Environ. Saf. 132, 318-328.

58. D. J. Finney Probit analysis, 3rd ed (Cambridge University Press, Cambridge, 1971).

59. X. B. Yan, J. T. Chen, J. Yang, Q. J. Xue, and P. Miele (2010). ACS. Appl. Mater. Interf. 2, (9), 2521-2529.

60. C. Hu, Y. Liu, Y. Yang, J. Cui, Z. Huang, and Y. Wang (2013). J. Mater. Chem. B. 1, 39-42.

61. X. Fan, G. Zhang, and F. Zhang (2015). Chem. Soc. Rev. 44, 3023-3035.

62. C. N. R Rao, U. Maitra and H. S. S. Ramakrishna Matte in C. N. R Rao and A. K. Sood (eds.), Synthesis, Characterization, and Selected Properties of Graphene (Wiley, New York, 2013)

63. D. Pan, J. Zhang, Z. Li, and M. Wu (2010). Adv. Mater. 22, 734-738.

64. D. Y. Pan, L. Guo, J. C. Zhang, C. Xi, Q. Xue, and H. Huang (2012). J. Mater. Chem. 22, (8), 3314-3318.

65. S. Zhuo, M. Shao, and S. T. Lee (2012). ACS. Nano. 6, (2), 1059-1064.

66. S. Wang, Z. Chen, I. Cole, and Q. Li (2015). Carbon 82, 304-313.

67. L. Jiao, X. Wang, G. Diankov, H. Hailiang Wang, and H. Dai (2010). Nat. Nanotechnol. 5, (5), 321-325.

68. F. Liu, M. Jang, H. Ha, J. Kim, Y. Cho, and T. Seo (2013). Adv. Mater. 25, 3657-3662.

69. G. Xie, K. Zhang, B. Guo, et al. (2013). Adv. Mater. 25, 3820-3839.

70. H. J. Sun, L. Wu, N. Gao, J. Ren, and X. G. Qu (2013). ACS. Appl. Mater. Interfaces. 5, 1174-1179.

71. A. Z. Mirakabadi, A. Sarzaeem, S. Moradhaseli, A. Sayad, and M. Negahdary (2012). Iran. J. Cancer. Prev. 5, (3), 109-116.

72. K. H. Liao and C. W. Macosko (2011). ACS. Appl. Mater. Interfaces. 3, (7), 2607-2615.

73. Y. S. Lin and C. L. Haynes (2010). J. Am. Chem. Soc 132, 4834-4842.

74. D. Napierska, L. C. J. Thomassen, V. Rabolli, D. Lison, L. Gonzalez, M. Kirsch-Volders, J. A. Martens, and P. H. Hoet (2009). Small 5, 846-853.

75. A. Mayer, M. Vadon, B. Rinner, A. Novak, R. Wintersteiger, and E. Frohlich (2009). Toxicology 258, 139-147.

76. J. Choi, V. Reipa, V. M. Hitchins, P. L. Goering, and R. A. Malinauskas (2011). Toxicol. Sci. 123, 133-143.

77. N. K. Arjunan, K. Murugan, C. Rejeeth, P. Madhiyazhagan, and D. R. Barnard (2012). Vector. Borne. Zoon. Dis 12, (3), 262-268.

78. M. Roni, K. Murugan, C. Panneerselvam, J. Subramaniam, and J. S. Hwang (2013). Parasitol. Res. 112, 981-990.

79. M. Govindarajan, M. Nicoletti, and G. Benelli (2016). J. Clust. Sci. 27, 745-761.

80. M. Govindarajan, S. L. Hoti, M. Rajeswary, and G. Benelli (2016). Parasitol. Res.. doi:10.1007/ s00436-016-5038-x.

81. P. Madhiyazhagan, K. Murugan, A. Naresh Kumar, T. Nataraj, D. Dinesh, C. Panneerselvam, J. Subramaniam, P. Mahesh Kumar, U. Suresh, M. Roni, M. Nicoletti, A. Abdullah Alarfaj, A. Higuchi, A. Murugan Munusamy, and G. Benelli (2015). Parasitol. Res.. doi:10.1007/s00436-015-4671-0.

82. J. Subramaniam, K. Murugan, C. Panneerselvam, K. Kovendan, P. Madhiyazhagan, D. Dinesh, P. Mahesh Kumar, B. Chandramohan, U. Suresh, R. Rajaganesh, Mohamad Saleh Alsalhi, S. Devanesan, M. Nicoletti, A. Canale, and G. Benelli (2016). Environ. Sci. Pollut. Res.. doi:10.1007/ s11356-015-6007-0.

83. E. Kweka, G. Zhou, T. Gilbreath, Y. Afrane, M. Nyindo, A. Githeko, and G. Yan (2011). Parasit. Vect. 4, 128.

84. G. Bowatte, P. Perera, G. Senevirathne, S. Meegaskumbura, and M. Meegaskumbura (2013). Biol. Control. 67, 469-474.

85. J. Subramaniam, K. Murugan, C. Panneerselvam, K. Kovendan, P. Madhi yazhagan, P. Mahesh Kumar, D. Dinesh, B. Chandramohan, U. Suresh, M. Nicoletti, A. Higuchi, J. S. Hwang, S. Kumar, A. A. Alarfaj, M. A. Munusamy, R. H. Messing, and G. Benelli (2015). Environ. Sci. Poll. Res. doi:10.1007/s11356-015-5253-5.

86. G. Benelli (2015). Parasitol. Res. 114, 3201-3212. 